\title{
Assessing hand hygiene practices in schools benefiting from the Ghana School Feeding Programme
}

\author{
Isaac Monney ${ }^{1}$, Oparebea Sussana Martinson ${ }^{1}$, Abugbilla Matthew Asampana ${ }^{1}$, Marfo Albert ${ }^{2}$ \\ ${ }^{1}$ Department of Environmental Health and Sanitation Education, University of Education, Winneba, Mampong Ashanti, Ghana \\ ${ }^{2}$ Department of Science Education, University of Education, Winneba, P.O. Box M40, Mampong Ashanti, Ghana
}

\section{Email address:}

monney.isaac@gmail.com (I. Monney), suzanamartinson@yahoo.com (O. S. Martinson), abugbila@gmail.com (A. M. Asampana), albertmarfo82@ymail.com (M. Albert)

\section{To cite this article:}

Isaac Monney, Oparebea Sussana Martinson, Abugbilla Matthew Asampana, Marfo Albert. Assessing Hand Hygiene Practices in Schools Benefiting from the Ghana School Feeding Programme. Science Journal of Public Health. Vol. 2, No. 1, 2014, pp. 7-14.

doi: $10.11648 /$ j.sjph.20140201.12

\begin{abstract}
School Feeding Programmes have been shown to impact positively on nutritional status and cognition of school children as well as hunger and poverty alleviation. There is however, dearth of information regarding hand hygiene in schools benefiting from these programmes. This study assesses hand hygiene practices, barriers and compliance to proper hand hygiene in schools benefiting from the Ghana School Feeding Programme (GSFP). Quantitative and qualitative data were collected through the administration of structured questionnaires and extensive field observation respectively. Fifty three (53) GSFP beneficiary schools were selected from four different locations in Ghana; Winneba (6), Mpraeso (10), Mampong-Ashanti (17) and Bolgatanga (20). Findings from the study indicate availability of hand washing facilities (HWFs) in most schools $(79 \% ; n=53)$; high pupil-to-HWF ratio resulting in poor hand washing practices (Range: 15-372; average: $105)$; availability of soap for handwashing $(83 \% ; n=42)$ but extensive use of shared containers $(53 \%$; $n=42)$; delays in acquisition of HWFs, fragmented private sector efforts in hand hygiene promotion and non-compliance with conventional hand washing practices. The study observes that the incorporation of schools into the GSFP without concurrently instituting a comprehensive hand washing programme is rather a retrogressive step considering the possible health repercussions on pupils. To avert this, it is proposed that hand washing with soap should be a mandatory practice in schools benefiting from the GSFP. This requires institution of a sustainable, impact-driven school hand hygiene programme involving both public and private sector agencies to be instituted along with the GSFP.
\end{abstract}

Keywords: Hand Hygiene, Soap, Ghana School Feeding Programme, Hand Washing Facility

\section{Introduction}

As part of the UN Millennium Development Goals (MDGs) adopted in 2000, world leaders and development agencies made an unprecedented commitment to halving the proportion of people suffering from extreme poverty and hunger by $2015[1,2]$. Since then, a number of impact-driven efforts and strategies have been implemented globally towards the achievement of this goal. Among these strategies is the provision of free school meals to poor children, in both less-developed and richer countries operated by the World Food Programme [3]. Estimates by the World Food Programme (WFP) based on 169 countries globally indicate that there are no less than 368 million school children fed every day at school [4]. Apart from the easily perceptible benefit of improving the nutritional status of school children [3,5], other literature have reported other wide ranging positive outcomes. In east and southern Africa, Bennet [6] reported that school feeding has been a major strategy to combat food shortages during crises such as drought or war. In Kenya, available literature [7] indicates that school feeding programs have played a crucial role in achieving the country's goal of universal primary education. Greenhalgh et al. [8] also reported significant improvement in growth and cognitive performance among school children while Alderman \& Bundy [9] argue that it influences both education of school children and supplements nutrition for their families.

In Ghana, School Feeding Programmes (SFPs) have their origins in the $1950 \mathrm{~s}$ where pupils in some primary and middle schools established by the Catholic Church were given food [10]. Though this effort contributed immensely 
to improving the nutritional status of school children, the impact was limited to only certain parts of Northern Ghana. However, this was given a major boost with the launching of the Ghana School Feeding Programme (GSFP) in late 2005. Supported by the WFP and the New Partnership for African Development /Hunger Task Force Initiative (NEPAD/HTFI), the programme principally aims at poverty reduction and improving food security in Ghana [11]. The programme was initially piloted in 10 schools in 2005 selected from each of the ten regions in Ghana. At the end of 2009, it had grown massively to serve 1,695 schools providing a nutritious meal every school-going day to approximately 650,000 school children nationwide [11].

Proponents of the programme $[10,11]$ have reported on the positive outcomes since its implementation viz. improvement in school enrolment, attendance and retention. There is, however, paucity of information on the promotion of hand washing with soap in schools benefitting from the programme. Globally, hand washing with soap has proven to be an effective mechanism to avert transmission of faeco-oral diseases and other infectious diseases in school children [12 - 14] but Setyautami et al. [15] argues that the practice in developing countries is still low This, according to recent studies $[16,17]$, is due to lack of adequate hand washing facilities (HWFs) in schools and poor hand washing practices even where they are present. The repercussions of this phenomenon are not far-fetched. Pengpid and Peltzer [18] asserts that respiratory infections and diarrhoeal disease which can be prevented by handwashing, are the biggest killers of young children in Africa. Without proper hand washing among beneficiaries of the GSFP, there is the likelihood of ingestion of contaminated food thereby transmitting diarrheal-causing pathogens [19].

It is against this backdrop that this paper generally examines the availability and adequacy of hand washing facilities in the beneficiary schools. It also looks at the barriers to hand washing and efforts by stakeholders in promoting hand washing among beneficiary schools. This is intended to contribute to efforts aimed at filling the knowledge gap in this regard and providing policy makers with a point of departure for developing and incorporating sustainable school hand hygiene programmes into the GSFP.

\section{Materials and Methods}

\subsection{Study Areas}

The study was conducted in four towns located in four regions in Ghana, namely, Winneba, Mpraeso, Mampong-Ashanti and Bolgatanta in the Central, Eastern, Ashanti and Upper East Regions of Ghana respectively. Winneba is the capital of the Effutu Municipal in the Central Region of Southern Ghana. Geographically, it lies on latitude $5^{\circ} 19^{\prime} 26^{\prime \prime} \mathrm{N}$ and longitude $0^{\circ} 40^{\prime} 02^{\prime \prime} \mathrm{W}$ with an estimated population of 60,000 people. Mampong-Ashanti is located on latitude $7^{\circ} 05^{\prime} 42^{\prime \prime} \mathrm{N}$ and longitude $1^{\circ} 24^{\prime} 49^{\prime \prime}$ $\mathrm{W}$ and serves as the capital of the Mampong Municipal
Assembly in the Ashanti Region of Ghana. It has an estimated population of 40,000 people. Mpraeso is the capital of Kwahu South District in the Eastern Region of Ghana with an estimated population of 10,000 people. It has geographical coordinates of $6^{\circ} 34^{\prime} 48^{\prime \prime} \mathrm{N} \quad 00^{\circ} 43^{\prime} 47^{\prime \prime} \mathrm{W}$. Bolgatanga doubles as both the regional capital of the Upper East Region of Ghana and the municipal capital of the Bolgatanga Municipal Assembly in the Northern part of Ghana. It has an estimated population of 70,000 people with geographical coordinates of $10^{\circ} 47^{\prime} \mathrm{N} 00^{\circ} 51^{\prime} \mathrm{W}$. These four regions are among the top six out of ten regions in Ghana with highest cases of acute diarrheal diseases among children under five years as reported by [20]. Particularly, the Upper East Region was reported to have the highest diarrhea cases among under- 5 year olds per 100,000 cases in 2011.

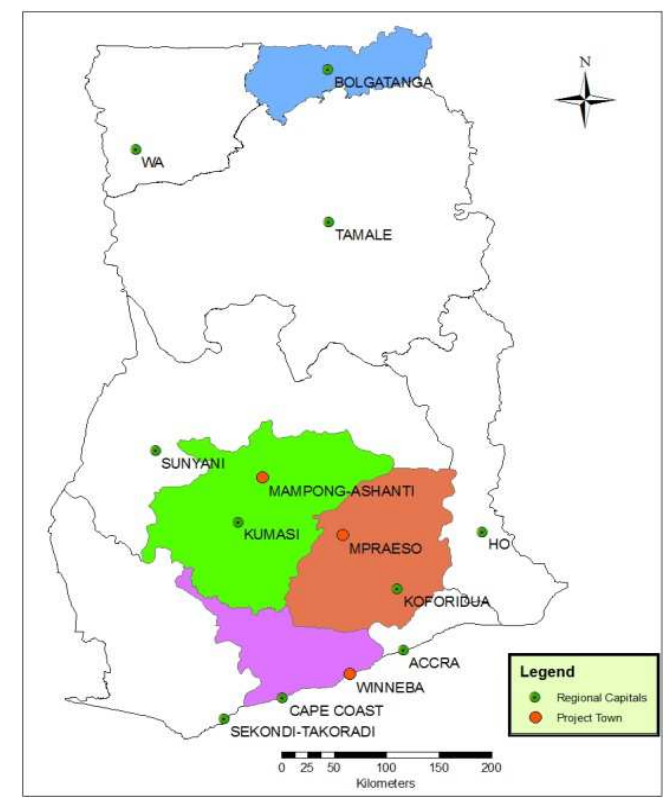

Figure 1. Map of Ghana showing locations of study areas

The study largely employed the descriptive approach based on information gathered from structured questionnaires consisting of both closed- and open-ended questions. This was supplemented by extensive observation of pupils in the selected schools with regards to their hand washing practices. At total of 53 GSFP beneficiary schools were used for the study. This consisted of 10 schools in the Kwahu South District out of 18 beneficiary schools, 17 schools in Mampong Municipality out of 49 beneficiary schools, 20 schools in the Bolgatanga Municipal Assembly out of 32 beneficiary schools and 6 out of 7 beneficiary schools in Winneba. Though a greater number of schools were initially anticipated to be used for the study, the reluctance of authorities to divulge information regarding the GSFP in some schools posed a huge constraint to the study. This could be attributed to the extensive reportage on the sub-optimal administration of the GSFP across the country $[1,11]$.

The study questionnaire was administered to headteachers 
of the beneficiary schools selected by simple random sampling. It was organized. The study questionnaire was organized into different sections to obtain information pertaining to the availability of hand washing facilities, the types and adequacy. The results from the study (quantitative data) were analysed with the Statistical Package for Social Sciences (SPSS), Version 16.0 using descriptive statistics such as frequencies and percentages.

\section{Results and Discussion}

\subsection{Availability of HWFs and Barriers to Hand Hygiene}

The findings from the study indicate a high dependence on the GSFP across the study areas. The number of pupils fed by the programme per school ranged between 204 and 404 with an average of 326 pupils per school as shown in Table 1.

Table 1: Pupils depending on the GSFP in study areas

\begin{tabular}{llll}
\hline Study areas & $\begin{array}{l}\text { Number of } \\
\text { schools } \\
\text { sampled }\end{array}$ & $\begin{array}{l}\text { Total } \\
\text { number of } \\
\text { pupils }\end{array}$ & $\begin{array}{l}\text { Average } \\
\text { number of } \\
\text { pupils per } \\
\text { school }\end{array}$ \\
\hline $\begin{array}{l}\text { Bolgatanga } \\
\text { Mampong- }\end{array}$ & 20 & 7483 & 374 \\
Ashanti & 17 & 5352 & 315 \\
Mpraeso & 10 & 2044 & 204 \\
Winneba & 6 & 2422 & 404 \\
Total & $\mathbf{5 3}$ & $\mathbf{1 7 , 3 0 1}$ & \\
\hline
\end{tabular}

A good proportion of the schools surveyed (79\%) had HWFs available (Table 2), possibly indicating that there have been efforts to, as a minimum, ensure hand washing among pupils in these schools. However, $17 \%$ of these schools $(n=42)$ lack soap at their HWFs (Table 3), particularly in Bolgatanga which has one of the highest average number pupils depending on the GSFP. According to Iyer et al. [21], washing hands with water and soap has the ability to effectively eliminate microbe-containing dirt from hands which would not be achieved by washing hands with soap. This practice, as established by Curtis and Cairncross [22], has the capacity to reduce the risk of diarrhoea by $47 \%$. It is in this regard that authors of various studies $[23,24]$ recommended that, apart from an adequate supply of potable water at a HWF, there should also be soap available at the facility. The findings of this study is however at variance with available literature $[16,25]$ which observed that a significant proportion of schools in a number of developing countries lack soap for hand washing.

Table 2: Availability of Hand Washing Facilities (HWFs)

\begin{tabular}{lll}
\hline Study areas & $\begin{array}{l}\text { Schools with } \\
\text { HWFs, n(\%) }\end{array}$ & $\begin{array}{l}\text { Schools without } \\
\text { HWFs, n(\%) }\end{array}$ \\
\hline Bolgatanga & $14(70 \%)$ & $6(30 \%)$ \\
Mampong-Ashanti & $12(71 \%)$ & $5(29 \%)$ \\
Mpraeso & $10(100 \%)$ & $0(0 \%)$ \\
Winneba & $6(100 \%)$ & $0(0 \%)$ \\
Total & $\mathbf{4 2 ( 7 9 \% )}$ & $\mathbf{1 1 ( 2 1 \% )}$ \\
\hline
\end{tabular}

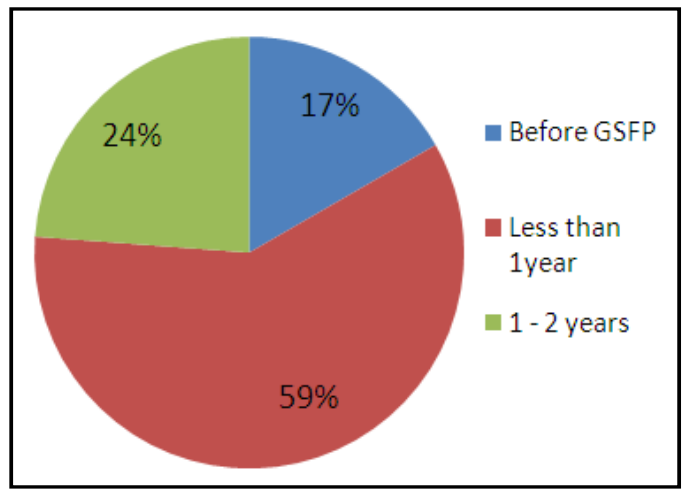

Figure 2: Disparity between incorporation into GSFP and provision of $H W F$

Proponents of hand washing with soap [21, 26], assert that the five critical times for hand washing are after defecation, after handling faeces, before preparing food, before feeding a child and before eating. However, the developers and implementers of the GSFP have lost sight of the importance of hand washing with soap prior to eating. This is corroborated by the fact that, HWFs are not concurrently provided in schools that are incorporated into the GSFP. As shown in Figure 2, in about a quarter $(24 \%)$ of the schools with HWFs $(n=42)$, the HWFs were provided after 12 - 24 months. Further, more than half $(59 \%)$ of the study schools with HWFs, acquired their HWFs in less than a year while only $17 \%$ had HWFs even before being incorporated into the GSFP (Figure 2). Even more unfortunate is the fact that there are currently $21 \%$ out of 53 study schools without any HWF (Table 2). The detrimental effects of this phenomenon on pupils' health and school attendance have been well documented [16, 27, 28]. Therefore, the provision of meals to pupils without simultaneously providing HWFs is rather a retrogressive step considering the adverse implications of pupils eating with filthy hands.

Table 3: Mode of hand washing in schools

\begin{tabular}{lll}
\hline Study areas & $\begin{array}{l}\text { Soap and water } \\
\text { (\% schools) }\end{array}$ & $\begin{array}{l}\text { Water only }(\% \\
\text { schools) }\end{array}$ \\
\hline $\begin{array}{l}\text { Bolgatanga } \\
(\mathrm{n}=14)\end{array}$ & 57 & 43 \\
$\begin{array}{l}\text { Mampong- } \\
\text { Ashanti } \\
(\mathrm{n}=12)\end{array}$ & 100 & 0 \\
$\begin{array}{l}\text { Mpraeso } \\
(\mathrm{n}=10)\end{array}$ & 100 & 0 \\
$\begin{array}{l}\text { Winneba } \\
(\mathrm{n}=6)\end{array}$ & 83 & 17 \\
Total & 83 & 17 \\
\hline
\end{tabular}

Provision of the HWFs in the schools is mainly from the Capitation Grant Scheme (CGS) although other Non-Governmental Organizations (NGOs), the Parent Teacher Associations (PTA) and Private Individuals also do same in some cases (Figure 3). The CGS is a scheme introduced by the Government of Ghana (GoG) in 2005 where public basic schools are given a predetermined 
amount of funds depending on the number of pupils enrolled, at just about US\$3.3 per pupil per year [29]. With the introduction of the CGS, studies [30,31] have shown that it has produced a knock-on effect on enrolment rates in various public schools country wide.

In approximately $83 \%$ of all the schools, the HWFs were provided using funds from the Capitation Grant. This confirms a study by Ampratwum and Armah-attoh [32] which cited hygiene and sanitation facilities as one of five key items on which the CG is expended. Particularly in schools benefitting from the GSFP, acquiring adequate HWFs is very essential since it promotes good hygiene behaviours. However, Akyeampong [29] argues that there are huge delays in the disbursement of funds to the various schools. This could explain the disparities between the periods for incorporation of schools into the GSFP and acquisition of HWFs discussed earlier. Considering the huge demands on the meagre Capitation Grant given annually to these schools, the acquisition of HWFs could be, if not the least, among the least priorities of headteachers who are in charge of expending the funds. Therefore, allocating funds specifically for the acquisition of HWFs and making hand washing with soap a mandatory practice in all schools benefiting from the GSFP would ensure that hand hygiene is progressively given some attention in order to achieve the full benefits of the programme. To achieve this a strong collaboration between the public and private sector institutions would be very important so as to augment existing government's efforts.

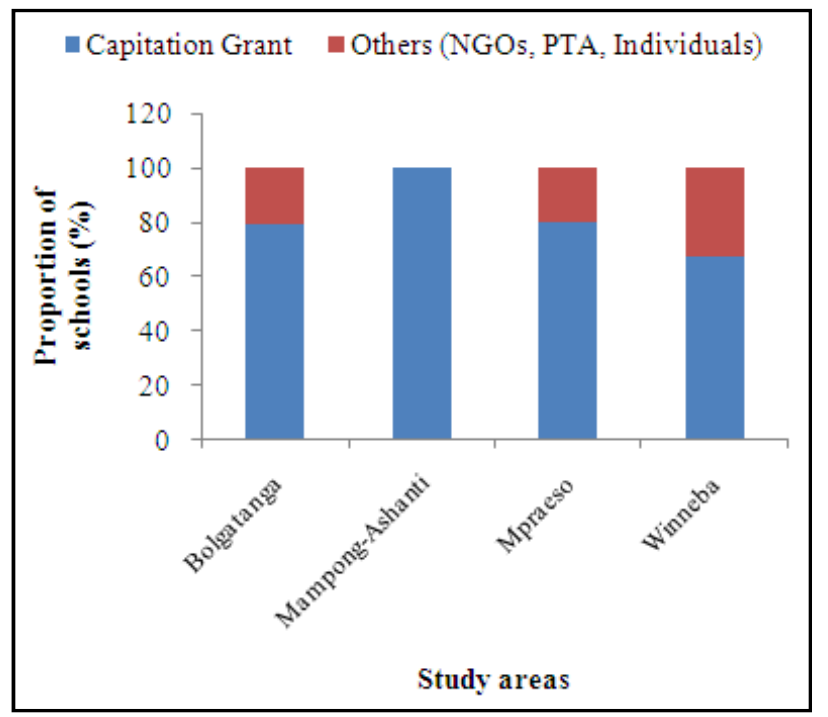

Figure 3: Source of funding for provision of $H W F S$

Three main types of HWFs; Veronica buckets, communal/shared basins and standpipes were found in the study schools with HWFs. In a few of the schools however, more than one type of HWF were being used. Communal basins were used in addition to standpipes whiles both communal basins and Veronica buckets (VBs) were used in other schools. A Veronica bucket (VB) is a large bucket of water with a faucet near the bottom and mounted on a wooden stand. It is sometimes provided with a wash basin below the faucet to act as a receptable for the foul water [33]. Approximately half (48\%) of the schools with HWFs used only VBs while 39\% used only communal/shared basins for hand washing (Figure 4). The dependence on VBs for hand washing in about half of the schools is encouraging since hand washing is generally recommended to be done under running water [34, 35]. However, extensive observation revealed that the volume of water stored in the VBs in some schools is not adequate for all pupils. Some pupils were left with no other option than to eat without washing their hands because the water in the VBs were exhausted.

The use of shared basins was particularly high in Bolgatanga where more than half $(57 \%)$ of the schools used shared basins. This practice is a departure from the conventions of proper hand washing. According to literature $[17,36]$, the use of shared basins for hand washing does not represent an adequate HWF even if it is used with soap. This is attributed to the multiple use of the same water by several people for hand washing.

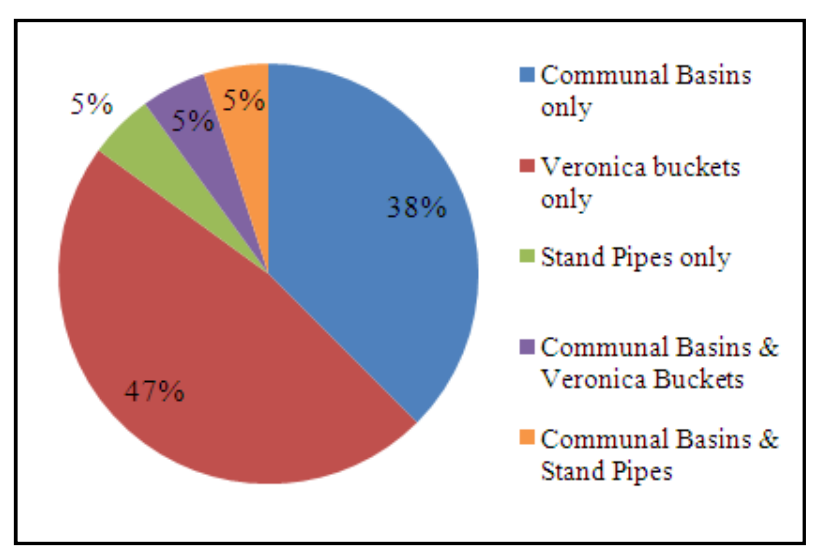

Figure 4: Types of HWFs in study schools $(n=42)$

Tay [37] posited that adequate and well functioning school sanitation and hand washing facilities play a major role in ensuring good hand washing practices. Further, access to a convenient hand washing facility has been found to be associated with higher rate of hand washing and decreased finger tips contamination [38]. Conversely, the findings from this study indicate grossly inadequate HWFs in various schools considering the huge number of pupils in these schools. On the average, approximately, 105 pupils depend on a HWF. Particularly, schools in Bolgatanga were found to have consistently high pupils-to-HWF ratio as depicted by the mean and median values of 148 and 142 respectively in Table 4 . As noticed from extensive personal observation, pupils are overcrowded at the HWFs during meals time resulting in cursory hand washing among pupils, as Greene et al. [28] puts it. Considering the struggle they have to go through to wash their hands, some pupils do not wash their hands at all before eating. Mirroring the results of this study, Snel [39] reported up to 167 pupils per HWF in Colombia while UNICEF [40] also reported average pupils-to-HWF ratios of 82 and 126 in the West Bank and 
Gaza respectively. The high pupils-to-HWF ratio in the study schools can be attributed to the explosion in school enrollments across the country due to the introduction of the GSFP as available literature indicate $[10,11,30,31]$.

Table 4: Pupils-to-HWF ratios in schools with HWFs

\begin{tabular}{lllll}
\hline $\begin{array}{l}\text { Study } \\
\text { areas }\end{array}$ & $\begin{array}{l}\text { Schools } \\
\text { with }\end{array}$ & \multicolumn{2}{l}{ Pupils-to-HWF ratio } & \\
\hline HWFs & Range & Median & Mean \\
\hline $\begin{array}{l}\text { Bolgatanga } \\
\text { Mampong- }\end{array}$ & 14 & $20-353$ & 142 & 148 \\
$\begin{array}{l}\text { Ashanti } \\
\text { Mpraeso }\end{array}$ & 12 & $16-372$ & 53 & 98 \\
Winneba & 6 & $15-230$ & 35 & 68 \\
\hline
\end{tabular}

Most schools with HWFs $(\mathrm{n}=42)$ depend predominantly on either boreholes $(36 \%)$ or pipe-borne water $(36 \%)$ while a few depend on surface water sources (17\%), hand-dug wells $(7 \%)$ and rainwater harvesting $(5 \%)$ for their daily water supply for hand washing (Table 5). However, these sources of water are mostly not within the premises of the schools and therefore pupils are tasked with the burden of conveying water from long distances for hand washing (Figure 5). This evidently poses a huge challenge to the practice of hand washing with soap as confirmed by [25]. Rainwater harvesting, which could provide water in close proximity to pupils is the least depended on for hand washing in the study schools (5\%).

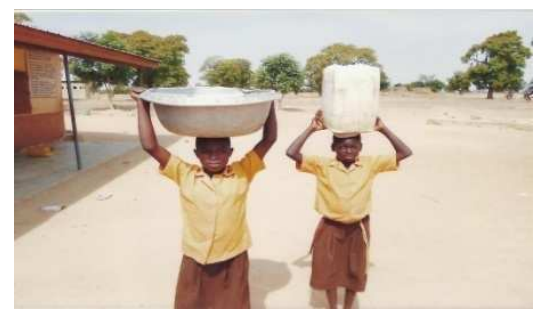

Figure 5: Pupils conveying water to school premises

Table 5: Source of water for hand washing

\begin{tabular}{llllll}
\hline $\begin{array}{l}\text { Study } \\
\text { areas }\end{array}$ & $\begin{array}{c}\text { BH } \\
(\%)\end{array}$ & $\begin{array}{c}\text { PBW } \\
(\%)\end{array}$ & $\begin{array}{c}\text { HDW } \\
(\%)\end{array}$ & $\begin{array}{c}\text { RWH } \\
(\%)\end{array}$ & $\begin{array}{c}\text { SW } \\
(\%)\end{array}$ \\
\hline $\begin{array}{l}\text { Bolgatanga, } \\
\mathrm{n}=14\end{array}$ & 79 & 21 & & & \\
$\begin{array}{l}\text { Mampong- } \\
\text { Ashanti, } \mathrm{n}=12\end{array}$ & 25 & 42 & & 8 & 25 \\
$\begin{array}{l}\text { Mpraeso, } \mathrm{n}=10 \\
\text { Winneba, } \mathrm{n}=6\end{array}$ & 10 & 30 & 30 & & 30 \\
Total & $\mathbf{3 6}$ & $\mathbf{3 6}$ & $\mathbf{7}$ & $\mathbf{5}$ & $\mathbf{1 7}$ \\
\hline
\end{tabular}

BH - Borehole PBW - Pipe-borne water HDW - Hand dug wells RWH - Rainwater Harvesting SW - Surface water

Close to three-quarters $(71 \%)$ of the study schools with HWFs obtain their daily water supply at no cost. The highest proportion of schools obtaining water freely was recorded at Bolgatanga (Figure 6). However, Bolgatanga has the highest proportion of schools without HWFs and also the highest proportion of schools using only water for hand washing.
This relationship is somewhat puzzling given that in other areas, school authorities purchase water and soap mostly from the Capitation Grant given to all schools across the country. In contrast to this finding, available literature [41, 42] allude the low level of hand washing to lack of access to water and soap. It is evident therefore that, even with the availability of water at no cost and the means to provide HWFs, some schools still lack HWFs.

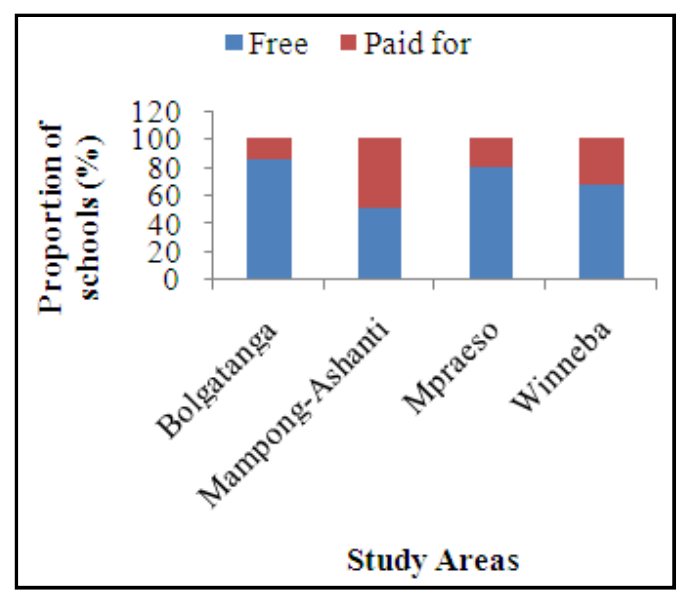

Figure 6: Acquisition of water for hand washing in schools

\subsection{Findings from Direct Observation}

Extensive observation of pupils in the study schools during meals time revealed poor hand washing methods even in schools using soap and water for hand washing. The mode of hand washing among almost all the pupils observed is in contrast to the conventions for hand washing as established in literature [21, 26]. A good proportion of pupils held their food in their left hand while washing only their right hands as shown in Figure 7. A few pupils who were observed to wash their hands properly however did so in communal basins, thereby contradicting the recommended guidelines for hand washing (Figure 8). Even in schools with VBs, a greater proportion of pupils did not wash their hands properly before eating. Teachers are mostly nowhere to be found during this time and therefore pupils hurriedly dip their hands in the water and proceed to eat their food. Pupils get overcrowded at the HWFs during these times affecting the efficiency of hand washing. Consistent with the findings of this study, Akyol et al. [43] argues that globally, adherence to hand hygiene recommendations is poor.

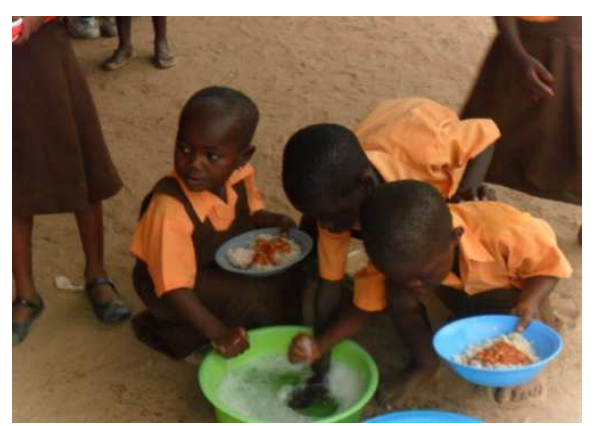

Figure 7: Children washing their hands during meals time 


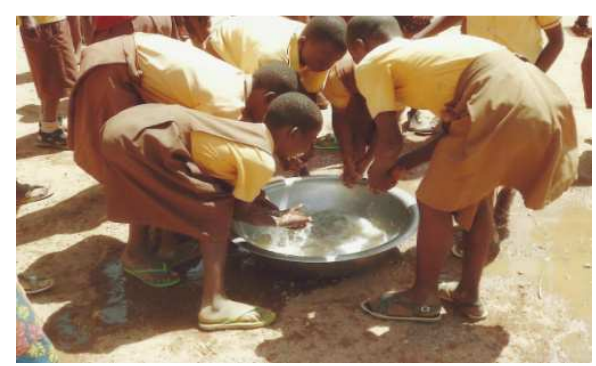

Figure 8: Pupils washing their hands in a shared basin

\subsection{Efforts to Promote Hand Hygiene in Schools}

Despite the abysmal level of hand hygiene practices in these schools, the Ministries of Education and Health, under the directive of the Government of Ghana, introduced a School Health and Education Program (SHEP) in 1992 [44]. This was primarily to provide comprehensive health education and services, as well as ensure availability and use of water and sanitation facilities in schools. In 2009 a SHEP policy was developed to provide clear institutional mandates and is currently being implemented in apparently all public schools nationwide. But the results of this study, corroborated by other studies in Ghana [17, 37], point out that the initiative has achieved minimal impact. Additionally, in 2003, as part of the global initiative for Public-Private Partnerships to Promote Handwashing with soap, the Community Water and Sanitation Agency (CWSA) in Ghana, in collaboration with development and private partners, launched the Ghana Public-Private Partnership to Promote Hand washing with Soap (GPPPHW). This initiative is aimed at, among others, increasing the practice of hand washing with soap at critical times among school children aged 5-16 years through education and provision of hand washing infrastructure [45,46]. Other Non-Governmental Organisations (NGOs) countrywide including Water and Sanitation for the Urban Poor (WSUP), Plan International, World Vision International, UNICEF and WaterAid also provide handwashing infrastructure for various schools across the country. Although all these efforts are in the right direction, they need to be cohesively implemented to produce the systemic impact of improving and sustaining hand hygiene practices in schools.

\section{Conclusions}

The study points out that hand hygiene in schools benefitting from the GSFP has not been holistically attended to. Although a significant proportion (79\%) of the study schools $(\mathrm{n}=53)$ have HWFs, they are grossly inadequate as depicted by the high average pupil-to-HWF ratio of 105 . Consequently, this results in overcrowding at the HWFs during meals time. The use of communal containers for hand washing by close to half of the schools with HWFs $(n=42)$ despite the widespread usage of soap and water for hand washing in $83 \%$ of the schools is also an affront to the practice of proper hand washing among pupils. Further, the study identified that the Capitation Grant Scheme is the major source of funds for the provision of HWFs in most schools $(83 \%)$ but the huge delays in the disbursement of funds affects the timely acquisition of the facilities. Only $17 \%$ of schools with HWFs acquired them before being incorporated into the programme whereas 59\% acquired HWFs in less than a year with the remaining proportion doing same between 1-2 years. Access to water is not a barrier since it is mostly acquired free of charge in most schools (71\%). Extensive field observation also revealed that pupils did not wash their hands properly as per the conventions of hand washing and did so generally without any form of supervision. Efforts to promote hand washing with soap among pupils through the SHEP and GPPPHW have thus failed to achieved the needed results with regards to these study schools. The study therefore affirms that the incorporation of schools into the GSFP without concurrently instituting a vital complementary service such as hand washing with soap is a retrogressive step with possible health repercussions on beneficiaries. It is proposed that, in the short-term, adequate HWFs should be provided to drastically reduce the pupil-to-HWF ratio in the study schools. Additionally, a sustainable School Hand Hygiene Programme should be instituted in tandem with the GSFP. This should be backed a strong political commitment and synergetic efforts by public and private sector agencies including the ministries of health, finance, local government, water authorities together with soap manufacturing companies, NGOs, PTAs and advocacy groups. Most importantly, the habit of hand washing with soap should be mandatory in schools benefiting from the GSFP augmented by intensive hand hygiene education and careful supervision by teachers. Further research should be conducted to determine the level of microbial contamination on pupils hands prior to taking their meals in order to provide the needed impetus for the provision of HWFs in these schools.

\section{References}

[1] P. Anderson, J. D. Moreen, G. Petersen and K. Tobey, 2005. Analysis of Regional Scalability of School Feeding Programs Using Locally-produced Foods in Ghana. International Business Development Program and United Nations Hunger Task Force URL: http://hgsf-global.org/ [Accessed on October 22, 2013]

[2] United Nations Department of Economic and Social Affairs, 2010. The Millennium Development Goals Report 2010. New York, USA.

[3] P. J. McEwan, 2013. The impact of Chile's school feeding program on education outcomes. Economics of Education Review, 32: 122- 139

[4] World Food Programme, 2013. State of School Feeding Worldwide. World Food Programme. Rome, Italy.

[5] L.H. Jomaa, E. McDonnell and C. Probart 2011. School feeding programs in developing countries: impacts on children's health and educational outcomes. Nutrition reviews, 692: 83-98. 
[6] J. Bennett, 2003. Review of School Feeding Projects. DFID, UK.

[7] N. Langinger, 2011. School Feeding Programs in Keynya: Transitioning to a Homegrown Approach. Stanford Journal of International Relations, 13 (1): 30 - 37

[8] T. Greenhalgh, E. Kristjansson and V. Robinson, 2007. Realist review to understand the efficacy of school feeding programmes. British Medical Journal, 335(7625): 858-861.

[9] H. Alderman and D. Bundy, 2011. School Feeding Programs and Development: Are We Framing the Question Correctly? The World Bank Research Observer, 27:204-221

[10] World Food Programme, 2007. Home-Grown School Feeding field case study: Ghana. Home-Grown School Feeding Project, World Food Programme. Rome, Italy.

[11] Partnership for Child Development/ Home Grown School Feeding, 2011. Home Grown School Feeding Technical Assistance Plan. URL: http://hgsf-global.org/en/bank/downloads/doc_download/29 1-ghana-technical-assistance-plan [Accessed on October 25, 2013]

[12] M. Guinan, M. McGuckin and Y. Ali, 2002. The effect of a comprehensive handwashing program on absenteeism in elementary schools. American Journal for Infection Control, 30 (4): 217-220.

[13] S.P. Luby, A.K. Halder, C. Tronchet, S. Akhter, A. Bhuiya and R.B. Johnston, 2009. Household characteristics associated with handwashing with soap in rural Bangladesh. The American Journal of Tropical Medicine and Hygiene, 81(5):882-887.

[14] L.T.T. Xuan and L. N. Hoat, 2013. Handwashing among schoolchildren in an ethnically diverse population in northern rural Vietnam. Global Health Action, doi: $10.3402 /$ gha.v6i0.18869

[15] T. Setyautami, S. Sermsri and J. Chompikul, 2012. Proper hand washing practices among elementary school students in Selat sub-district, Indonesia. Journal of Public Health and Development, 10 (2): 3 - 20

[16] C. Lopez-Quintero, P. Freeman and Y. Neumark, 2009. Hand Washing Among School Children in Bogotá, Colombia. American Journal of Public Health, 99(1): 94-101.

[17] M. Steiner-Asiedu, S.E. Van-Ess, M. Papoe, J. Setorglo, D.K. Asiedu and A.K. Anderson, 2011. Hand Washing Practices among School Children in Ghana. Current Research Journal of Social Sciences, 3(4): 293-300.

[18] S. Pengpid and K. Peltzer, 2012. Hygiene behaviour and health attitudes in African countries. Current Opinion in Psychiatry, 252:149-154.

[19] Ejemot, R.I., Ehiri, J.E., Meremikwu, M. M. \& Critchley, J.A 2008. Hand washing for preventing diarrhoea. Cochrane database of systematic reviews. 23(1). doi: $10.1002 / 14651858$

[20] Ghana Health Service, 2011. 2011 Annual Report. URL: http://www.ghanahealthservice.org/ [Accessed on October $28,2013]$

[21] P. Iyer, J. Sara, V. Curtis, B. Scott and J. Cardosi, 2005. The Handwashing handbook: A guide for developing a hygiene promotion program to increase hand washing with soap. The World Bank Group, Washington DC, USA.

[22] V. Curtis and S. Cairncross, 2003. Water, Sanitation \& Hygiene at Kyoto: Handwashing and sanitation need to be marketed as if they were consumer products. British Medical Journal, 327 (7405): 3-4

[23] S. Kesevan, S. Barodawala and G.P. Mulley, 1998. Now wash your hands? A survey of hospital hand wash washing facilities. Journal of Hospital Infections, 40: 291-293.

[24] R. S. K. Hulland, E. Leontsini, R. Dreibelbis, L. Unicomb, A. Afroz, C. N. Dutta, F. A. Nizame, S.P. Luby, P. K. Ram and P. J. Winch, 2013. Designing a handwashing station for infrastructure-restricted communities in Bangladesh using the integrated behavioural model for water, sanitation and hygiene interventions. BMC Public Health, 13:877 doi:10.1186/1471-2458-13-877

[25] V.A. Curtis, L.O. Danquah and V.R. Aunger, 2009. Planned, motivated and habitual hygiene behaviour: an eleven country review. Health Education Research, 24(4) 655-673

[26] S. P. Luby, A. K. Halder, T. Huda, L. Unicomb and R. B. Johnston, 2011. The Effect of Handwashing at Recommended Times with Water Alone and With Soap on Child Diarrhea in Rural Bangladesh: An Observational Study. PLoS Medicine. 8(6) doi: 10.1371/journal.pmed.1001052

[27] C. Jasper, L. Thanh-Tam, and J. Bartram, 2012. Water and Sanitation in Schools: A Systematic Review of the Health and Educational Outcomes. International Journal of Environmental Research and Public Health. 9(8): 2772-2787

[28] L. E. Greene, M.C. Freeman, D. Akoko, S. Saboori, C. Moe and R. Rheingans, 2012. Impact of a School-Based Hygiene Promotion and Sanitation Intervention on Pupil Hand Contamination in Western Kenya: A Cluster Randomized Trial. The American Journal of Tropical Medicine and Hygiene. 87(3): 385-393.

[29] K. Akyeampong, 2011. Reassessing the impact of school capitation grants on educational access in Ghana. Consortium for Educational Access, Transitions and Equity, Research Monograph, 7: 1

[30] R. D. Osei, G. A. Owusu, F. E. Asem and R. L. Kotey, 2009. Effects of Capitation Grant on Education Outcomes in Ghana ISSER, Global Development Network. URL: www.researchgate.net [Accessed on October 28, 2013]

[31] A. K. Osei-Fosu, 2011. Evaluating The Impact of The Capitation Grant and The School Feeding Programme on Enrollment, attendance and Retention in Schools: The Case of Weweso Circuit. Journal of Science and Technology, 31 (1): $55-64$

[32] E. Ampratwum and D. Armah-attoh, 2010. Tracking Capitation Grant in Public Primary Schools in Ghana. Ghana Center for Democratic Development. Briefing Paper, 10 (1): 1-8

[33] Ghana Together 2012. Health and Sanitation Projects. URL: http://ghanatogether.org/HTML/Projects/Sanitation.html [Accessed on October 30, 2013]

[34] Centers for Disease Control and Prevention, 2007. Hand-Washing Recommendations to Reduce Disease Transmission From Animals in Public Settings. URL: http://www.cdc.gov/mmwr/preview/mmwrhtml/rr5605a4.ht $\mathrm{m}$ [Accessed on November 4, 2013] 
[35] P. Mathur, 2011. Hand Hygiene: Back to the Basics of Infection Control. Indian Journal of Medical Research, 134(5): 611-620.

[36] B. Scott, D.W. Lawson and V. Curtis, 2007. Hard to handle: Understanding mother's handwashing behaviour in Ghana. Health Policy Planning, 22: 216-224.

[37] V. Tay, 2005. The Child Health Millennium Development Goal: What Water, Sanitation and Hygiene can do in Ghana WELL Country Note 3.2. WEDC, UK.

[38] A. Biran, 2011. Enabling Technologies for Handwashing with Soap: A Case Study on the Tippy-Tap in Uganda. Global Scaling Up Handwashing Project. WorldBank's Water and Sanitation Program. Working Paper URL: http://wsp.org/ [Accessed on November 5, 2013]

[39] M. Snel, 2004. The Worth of School Sanitation and Hygiene Education: Case studies. IRC International Water and Sanitation Centre, Delft. The Netherlands.

[40] UNICEF, 2012. School Water Sanitation and Hygiene Knowledge, Attitudes and Practices Survey. United Nations Children's Fund Office, Palestine.

[41] B. Marjadi, and M. L. McLaws, 2010. Hand hygiene in rural Indonesian healthcare workers: barriers beyond sinks, hand rubs and in-service training. The Journal of Hospital Infection. 76(3):256-260

[42] J. Greenwell, J. McCool, J. Kool and M. Salusalu, 2013. Typhoid fever: hurdles to adequate hand washing for disease prevention among the population of a peri-urban informal settlement in Fiji. Western Pacific Surveillance and Response Journal. 4(1):41-45

[43] A. Akyol, H. Ulusoy, and I. Ozen, 2006. Handwashing: a simple, economical and effective method for preventing nosocomial infections in intensive care units. The Journal of Hospital Infection. 62(4): 395-405

[44] A. Marieke and K. Tyhra 2013. Sustainability Index of WASH Activities \& Partnership Evaluation: Sustainability Index Country Report for Ghana. Rotary International, USAID.

URL: http://www.washplus.org/sites/default/files/ghana_sustainabi lity.pdf [Accessed on November 18, 2013]

[45] UNICEF, 2013. Case study: Public-private partnership to promote handwashing in Ghana. URL: http://www.unicef.org/wcaro/overview_2765.html [Accessed on November 11, 2013]

[46] CWSA 2013. Handwashing education. URL: http://www.cwsagh.org/ [Accessed on November 1, 2013] 